\section{Development and recent progresses of gene therapy for $\beta$-thalassemia}

\author{
Santina Acuto, Elena Baiamonte, Rosalia \\ Di Stefano, Barbara Spina, Rita Barone, \\ Aurelio Maggio \\ UOC Ematologia per le Malattie Rare del \\ Sangue e degli Organi Ematopoietici, \\ Dipartimento di Oncologia ed \\ Ematologia, AO Ospedali Riuniti Villa \\ Sofia-Cervello, Palermo, Italy
}

\section{Abstract}

$\beta$-thalassemias are among the most common inherited monogenic disorders worldwide due to mutations in the $\beta$-globin gene that reduce or abolish the production of the $\beta$-globin chain resulting in transfusion-dependent chronic anemia. Currently, the only curative treatment is allogeneic hematopoietic stem cells (HSCs) transplantation, but this option is limited by the availability of HLA-matched donor. Gene therapy, based on autologous transplantation of genetically corrected HSCs, holds the promise to treat patients lacking a compatible bone marrow donor. Initial attempts of gene transfer have been unsuccessful due to limitations of available vectors to stably transfer a globin gene in HSCs and reach high and regulated expression in the erythroid progeny. With the advent of lentiviral vectors (LVs), based on human immunodeficiency virus, many of the initial limitations have been overcome. Since 2000 when Sadelain and co-workers first demonstrated successful globin gene transfer in murine thalassemia models with improvement of the phenotype using a recombinant $\beta$ globin $/ \mathrm{LV}$, several other groups have developed different vectors encoding either $\beta, \gamma$ or mutated globin genes and confirmed these results in both murine models and erythroid progeny derived from patient's HSCs. In light of these encouraging results, research has recently moved into clinical trials that are ongoing or soon to begin. One participant in an ongoing gene transfer trial for $\beta$-thalassemia has achieved clinical benefit with elimination of his transfusion requirement. Here, development and recent progress of gene therapy for $\beta$-thalassemia is reviewed.

\section{$\beta$-thalassemia}

$\beta$-thalassemias represent the most common monogenic disorders worldwide with 80 million carriers of the trait and a global birth-rate incidence of 40,000/year, most prevalent in the Mediterranean region, the Middle East, India, and South East Asia. In Italy alone, there are over 5000 patients and about 1.5 million carriers of the trait.1,2 These syndromes arise from more than 200 autosomal recessive mutations that affect the human $\beta$-globin gene leading to the absence or insufficient production of hemoglobinA $(\mathrm{HbA}) \beta$-chains. This in turn leads to an imbalance of $\alpha$ - and $\beta$-globin chains, resulting in excess of $\alpha$-chain molecules which precipitate in red blood precursors, leading to impaired erythrocyte maturation, mechanical damage, and ultimately to apoptosis. ${ }^{3}$

Homozygotes or heterozygotes compound harboring either null or very low expressing alleles present severe anemia that becomes evident a year after birth, and that is lethal early in life if left untreated.

\section{Current therapies}

Palliative therapies consist of regular blood transfusions in combination with daily iron chelation life-long. Hydroxyurea treatment for fetal hemoglobin (HbF) induction has also been employed in $\beta$ thalassemia patients, but only some patients, with thalassemia intermedia showed significant improvement in total hemoglobin levels and for a short time of treatment. ${ }^{4}$

Although an appropriate scheme of transfusion and chelation have improved life expectancy of patients and significantly delayed the onset of iron-related organ failure, the lifelong treatment severely compromises the quality of life of thalassemia patients. Treatment noncompliance is common and many patients suffer from cardiac, hepatic and endocrine complications. ${ }^{5}$ Moreover, higher incidence of new complications, as hepatocarcinoma, has been described probably as a result of improvement in thalassemia outcomes. ${ }^{6}$ The management of the disease and its complications constitutes an enormous financial effort affecting in particular the developing countries; ${ }^{7}$ in fact a proper medical therapy for thalassemia requires expertise for associated complications and the support of an increasing number of new technologies (e.g., cardiac magnetic resonance imaging, etc.). ${ }^{8}$

Considering that the vast majority of patients today lives in non-industrialized countries, where these effective therapies are improving but are still severely curtailed, the problem of relative costs between a lifelong medical therapies versus a therapy intended to cure is crucial.

\section{Allogeneic hematopoietic stem cell transplantation}

Allogeneic hematopoietic stem cell transplantation (HSCT) is the only possible curative
Correspondence: Santina Acuto, U.0.C Ematologia per le Malattie Rare del Sangue e degli Organi Ematopoietici, A.0. Ospedali Riuniti Villa Sofia-Cervello, via Trabucco 180, 90146 Palermo, Italy.

Tel.: +39.091 .6802433 - Fax: +39.091 .6880828 .

E-mail: santina.acuto@villasofia.it

Key words: gene therapy, $\beta$-thalassemia, hematopoietic stem cells, lentiviral vectors.

Acknowledgments: we thank Giuseppe Damiano and Alice Pecoraro for their help in reviewing the manuscript. This work was supported by Fondazione Franco e Piera Cutino and Assessorato Regionale delle Attività Produttive - Regione Sicilia, LR23 (project: RIMEDRI).

Contributions: SA, EB, RDS and BS have equally contributed to write the paper; $\mathrm{RB}$ and $\mathrm{AM}$ contributed to comment and edited the paper.

Conflict of interests: the authors declare no potential conflict of interests.

Received for publication: 21 February 2014.

Revision received: 15 April 2014.

Accepted for publication: 20 May 2014.

This work is licensed under a Creative Commons Attribution 3.0 License (by-nc 3.0).

(C) Copyright S. Acuto et al., 2014

Licensee PAGEPress, Italy

Thalassemia Reports 2014; 4:2925

doi:10.4081/thal.2014.2925

treatment for $\beta$-thalassemia major. The defective gene is replaced by the normal hematopoietic cells from donors. Since the first report of a successful HSCT from an HLA-identical sibling in a child with homozygous $\beta$-thalassemia in $1982^{9}$ more than 3000 patients worldwide have received allogeneic HSCT as curative treatment for $\beta$-thalassemia major. This therapeutic treatment was developed and grew into accepted routine clinical practice primarily thanks to the Pesaro group experience during the 1980 s and early 1990 s, that developed a prognostic scheme to predict transplant outcome in patients. A remarkable result of 82 $93 \%$ of disease-free survival is achieved if a matched sibling donor is available, and if the patient belongs to the class 1 and 2 of the Pesaro's classification and is younger than 17 years of age. This favorable result cannot be reproduced in older, more heavily iron-overloaded patients. Transplantations from matched-unrelated donors, haploidentical donors, or in patients with disease in later stage are associated with significantly lower disease-free survival (21-70\%) and higher morbidity and mortality (25-30\%). ${ }^{10,11}$

The development of new techniques to improve the management of graft versus-host 
disease (GVHD), and to perform HSCT from unrelated donors or cord blood stem cells may expand the pool of potential donors in the near future; currently they remain largely investigational. ${ }^{12-14}$ Because of these significant disadvantages, and shortage of suitable donors, HSCT is limited to less than one third of the patients; for the vast majority of thalassemic subjects lacking an HLA-matched donor, clinical improvement or even a final cure might be achieved by gene therapy approaches.

\section{Gene therapy of $\beta$-thalassemia}

The goal of globin gene therapy is to restore the capacity of the thalassemic subject's own HSCs to generate red blood cells containing normal hemoglobin level which will reverse the ineffective erythropoiesis and correct the inherited anemia. This therapeutic way consists of a normal globin gene transfer into autologous HSCs. The transfer is virtually applicable to all patients with no risk of GVHD or immunological complications since the graft is autologous. HSCs recovered from bone marrow (BM) or mobilized peripheral blood (PBMCs) are thus the target for ex-vivo globin gene transfer, as these cells are the only ones capable to self-renew and generate all hematopoietic lineages including the erythroid one. ${ }^{15,16}$

The gene therapy treatment plane consists of the follow steps summarized in Figure 1: i) collection of the subject's hematopoietic CD34+ stem and progenitor cells from BM or PBMC; ii) ex-vivo transduction with globin gene/recombinant vectors under appropriate culture conditions; iii) reinfusion of the transduced CD34+ cells after a preparative regimen able to promote the engraftment and expansion of the corrected HSCs; and iv) follow up the post-treatment period to monitor the safety of the procedure, the occurrence of engraftment and the expression of the globin transgene. The development of gene transfer methods for the treatment of thalassemia by various types of vectors has been a challenge for more than three decades; to date most efforts have focused on the development of recombinant retroviral vectors as mean of gene delivery into stem cells. ${ }^{17,18}$

These vectors, based on $\gamma$-retroviruses $(\gamma$ $\mathrm{RV}$ ) or lentiviruses (LV), are widely used in the setting of hematopoietic gene therapy because of their ability to efficiently integrate therapeutic genes into the target cell genome, resulting in long term gene transfer even after many rounds of cellular division. ${ }^{19}$

Even if $\beta$-thalassemias are among the first diseases for which gene therapy was envisioned, the addition of a globin gene, mediated by retroviral vectors, raises major challenges in terms of controlling transgene expression. In fact, to made gene therapy of $\beta$-thalassemia effective, safe and realistic as therapeutic

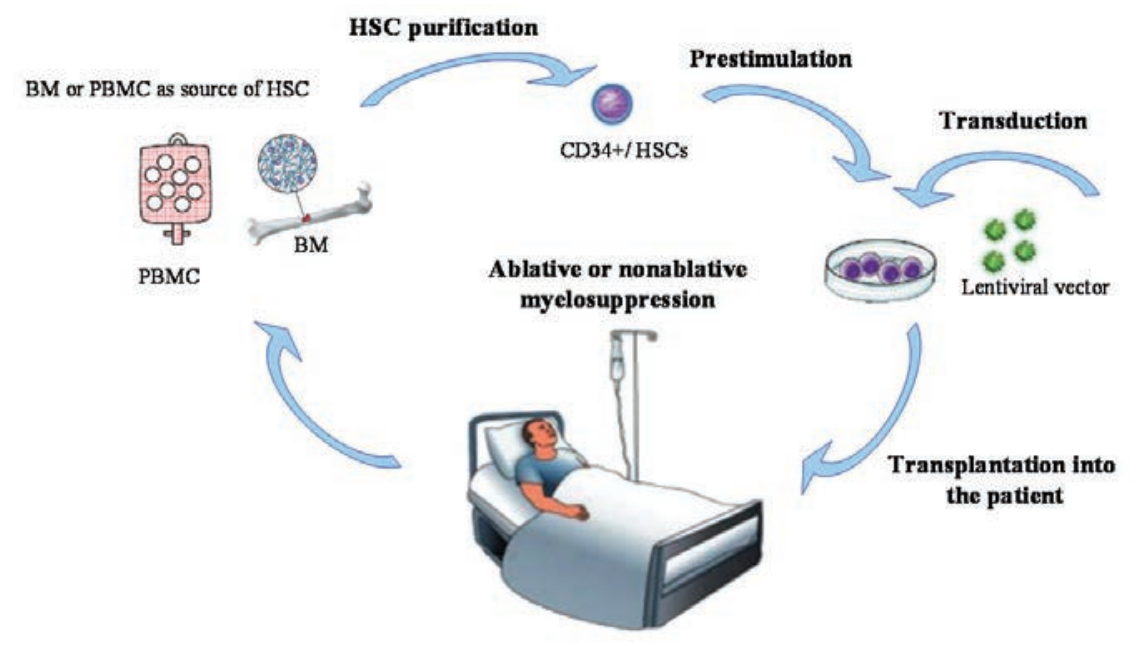

Figure 1. Schematic representation of hemopoietic stem cell (HSC)-based gene therapy for $\beta$-thalassemia. HSCs collected from bone marrow (BM) or from peripheral blood mononuclear cells (PBMC) after mobilization, are processed to purify CD34+ hematopoietic stem cells (HSC purification). The cells are cultured in early-acting cytokines (prestimulation) and transduced with a therapeutic globin lentiviral vectors designed to express high levels of normal human $\beta$-globin (transduction). The patient is treated with ablative or non-ablative myelosuppression, and then engrafted with the vector-modified cells (transplantation).

approach, some fundamental conditions have to be fulfilled: i) the therapeutic vector should exhibit high titer and ability to efficiently transduce HSCs and the genome of the vector should be stably transmitted; ii) the expression of the transgene must be controlled through the use of regulatory elements in order to be erythroid-specific, stage-restricted, elevated, independent, and sustained over time; iii) the therapy itself must be safe (e.g., absent or low vector genotoxicity).

\section{Development of effective vectors for $\beta$-thalassemia gene therapy}

\section{$\gamma$-retroviral vectors}

Early attempts back in the 1980s and 1990s utilized $\gamma$-RV vectors derived from murine leukemia virus (MLV) to drive expression of $\beta$ globin genes into murine HSCs. The transfer of a complete globin gene into murine stem cells has been accomplished, but the level of expression remained relatively low, reaching $0 \%-2 \%$ of the endogenous RNA level..$^{20-22}$

In an attempt to increase $\beta$-globin expression, Novak et al..$^{23}$ incorporated the newly identified powerful DNA-enhancer elements from the $\beta$-globin locus control region (LCR) into MLV vectors; This genomic element was discovered in transgenic mice experiments by virtue of its functional activity in providing copy number-dependent, integration site- independent globin gene expression in erythroid cells. ${ }^{24}$ In its native configuration, the $\beta$ globin LCR is too large to be included in retroviral vectors, therefore, the functional hypersensitive sites (HS2, HS3, and HS4) upstream from the $\beta$-globin gene cluster has been adapted to minimize the size of vectors by focusing on the core.

Unfortunately, the inclusion of LCR core elements, although significantly increase the expression levels in murine erythroleukemia cells, significantly lowers the titer of the vectors and makes them genetically unstable. ${ }^{25,26}$ The latter, frequently occurs due to activation of cryptic splice sites of the LCR sequence in the RV RNA, and additional attempts were done to eliminate these sites. Leboulch et al., after extensive mutagenesis studies of the transduced $\beta$-globin gene, identified a 372 bp intronic segment and multiple polyadenylation and splicing sites, that were responsible for low viral titers and instability of proviral transmission, upon infection. ${ }^{27}$ Even when small segments of the LCR element were included without these problems, the resulting vectors exhibited variable expression patterns, indicating sensitivity to position effects. ${ }^{28}$ Incorporation of chromatin insulators improved the expression and stability of RV vectors, but their expression still remained well below therapeutic levels. ${ }^{29}$

Another major limitation is that the $\gamma$ RV vectors need to infect cells before or close to their division, because the viral RNA cannot pass through the nuclear membrane. Since the majority of hematopoietic stem cells are in a 
quiescent state, it is necessary to stimulate them with cytokines to induce cell division and achieve higher transduction efficiency; on the other hand, the stimulation of quiescent hematopoietic stem cells impairs the longterm repopulating capacity. ${ }^{30}$

In general, the extensive efforts over nearly two decades for the development of effective $\beta$ globin/ $\gamma$ RV vectors have had limited success, ${ }^{31}$ but eventually paved the way for the success of gene therapy.

\section{Lentiviral vectors}

In the mid-1990s, the HIV-1 based LV vector became available and offered a real alternative to $\gamma$-RV vectors as possible carriers of globin genes. As opposed to $\gamma$-RV, LV vectors have the ability to transduce non-dividing cells and can carry large transgene cassettes (9-10 kb) with introns and regulatory LCR elements with none or limited sequence rearrangement. Therefore, LV vectors are thus likely to be selected as vectors of choice for the stable delivery of regulated transgenes in stem cellbased gene therapy. ${ }^{32,33}$

Since their introduction, these vectors underwent many improvements, including the reduction of HIV sequences including the viral enhancer; a self-inactivating (SIN) vector design that eliminates expression of the viral sequences by deleting the U3 enhancer region of the viral long-terminal repeat (LTR) was introduced.$^{34}$ With such a SIN vector design, vector expression can thus be driven exclusively by erythroid-specific enhancers and promoters; in turn, this allows for elevated, tissue restricted globin gene expression and increases safety profile by reducing the potential for vector sequences to activate the expression of cellular genes in most tissues. ${ }^{35,36}$

A prototypical $\beta$ globin/ $/ \mathrm{LV}$ self-inactivating vector is depicted in Figure 2.

In addition, as documented both in cell lines and in large animal models, HIV-derived vectors possess a safety advantage over those derived from MLV because of their natural propensity to integrate all along transcription units without preference for promoter regions. ${ }^{37-39}$ These differences in integration patterns have now been verified in human clinical trials via large-scale insertion site analyses. ${ }^{40-43}$

\section{The use of chromatin insulators to} improve the expression and safety of integrating gene transfer vectors

$\mathrm{LV}$ vectors, although to a lesser degree compared to the $\gamma$-RV vectors, are subject to chromosomal position effects leading to transgene silencing or variegated expression. The reduced versions of the $\beta$-globin LCR are apparently insufficient to overcome position-dependent variability of gene expression in erythroblasts.

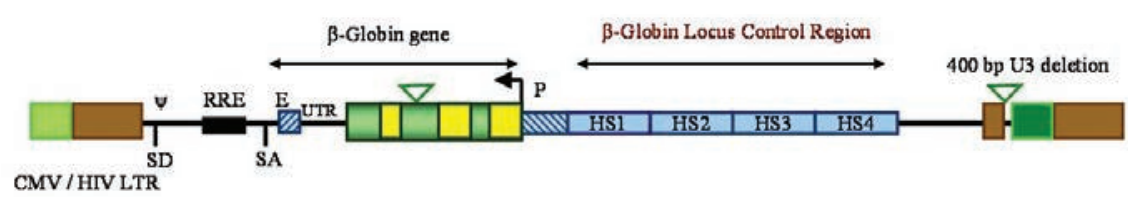

Figure 2. General scheme of a prototypical $\beta$-globin lentiviral self-inactivating vector. The vector consists of viral and human $\beta$-globin gene sequences. Viral sequences: viral packaging signal $(\psi)$; donor $(\mathrm{SD})$ and acceptor (SA) splicing sites; viral Rev responsive element (RRE). $\beta$-globin gene sequences: a combination of 2 to 4 core sequences from DNase hypersensitive (HS) sites (HS1, HS2, HS3, HS4); $\beta$-globin gene body including from 200 to $400 \mathrm{bp}$ of promoter sequences $(P)$; a stabilizing $372 \mathrm{bp}$ RsaI deletion of IVS2 (RsaI); variable length of the 3'untraslated region (UTR); the enhancer region contained in a PstI fragment 3 , to the $\beta$-globin gene (E). Safety modifications include stop codons in the $\psi$ signal and a $400 \mathrm{bp}$ deletion in the $\mathrm{U} 3$ region of the 3'long terminal repeat (LTR).

The use of chromatin insulators offers a potential solution for generating vectors more effective and safer; insulator elements can act as barrier elements to dampen position effects and enhancer blockers to prevent nearby genes deregulation. The prototypic chromatin insulator from chicken $\beta$-globin gene locus, cHS4, reduces the silencing chromosomal position effects providing a more consistent/uniform expression, and therefore leading to superior genetic correction in both animal models and cell cultures. ${ }^{44}$ Moreover, this element alone or in combination with other elements has been shown to have a lower propensity to perturb gene expression of neighboring genes. ${ }^{44}$ Unfortunately, the caveat is that $\mathrm{LV}$ vectors carrying the full length (1.2 bp) cHS4 element dramatically reduces vector titers which is another very important aspect in hematopoietic stem cell gene transfer; smaller versions of this element do not retain the full insulator activity. In the attempt to expand the repertoire of available elements that lead to higher, potentially therapeutic levels of the human globin genes, several groups, including ours, have identified new sequences functioning as chromatin insulators. $^{44-48}$ Our group focused on an element derived from the sea urchin histone gene locus, termed sns5 (462 bp long); its inclusion in a $\gamma$ $\mathrm{RV}$ reporter vector made it even more resistant to silencing position effects than the cHS4 insulator itself in an erythroid cell line model. As the cHS4 element, sns5 displays enhancer-blocking insulator activity and has the ability to recruits epigenetic markers of active chromatin in erythroid milieu, making it potentially an ideal candidate to improve globin/recombinant vectors efficacy. ${ }^{47}$

\section{Preclinical studies}

\section{Correction of $\beta$-thalassemia on mouse model}

The major breakthrough in the correction of $\beta$-thalassemia came from the group of Sadelain in New York. They reported the first recombinant $\beta$-globin/LV vector, termed TNS9, capable to accommodate more complex transcription units without compromising the titer. The TNS9 vector carried a much larger ( $3.2 \mathrm{~kb})$ LCR than that previously carried by globin/ $\gamma \mathrm{RV}$ vectors; it results from a combination of the most transcriptionally active elements HS2, HS3, and HS4 linked to a $\beta$-globin gene plus its 3' enhancer. ${ }^{49}$

The greater functionality of this larger $\beta$ LCR element combination gave rise to a much higher average level of $\beta$-globin expression (4-6 g/dL per vector copy) resulting in amelioration of severe $\beta$-thalassemia intermedia and thalassemia major on mouse models. ${ }^{49,50}$

Since these initial reports, several other groups have confirmed and extended these results in models of thalassemia using $\mathrm{LV}$ encoding $\beta$ - or $\gamma$ - or mutated globin gene. ${ }^{36,51-53}$

In addition, Miccio and co-workers showed that genetically corrected thalassemic erythroblasts undergo to in vivo selection in mice, indicating that the corrected cells have a survival advantage over the thalassemic ones. ${ }^{54}$ From a clinical point of view, this advantage could imply a lower myeloablative regimen for a patient undergoing to gene therapy, who could benefit even when some chimerism persists after BM transplant with genetic modified cells.

\section{Correction of human thalassemic erythroid cells}

In vitro model of human erythropoiesis have been developed for preclinical evaluation of $\beta$ globin/LVs to assay for production of $\mathrm{HbA}$ after gene delivery into CD $34^{+}$cells obtained from mobilized peripheral blood of normal adults or steady-state BM from patients with $\beta$-thalassemia major. Production of normal amounts of $\beta$-globin with correction of ineffective erythropoiesis has been achieved in erythroid progeny of $\beta$-thalassemic CD $34^{+}$cells and 
effective human erythropoiesis was documented 3-4 months after transplantation of these gene-corrected primitive cells into immunedeficient mice. ${ }^{55}$ Another study that used CD34+ cells collected from a large cohort of patients provided additional evidence that the $\beta$-thalassemia major phenotype may be corrected by gene transfer. ${ }^{56}$

An additional concern associated with the attempt to cure hemoglobinopathies by gene transfer is the number and complexity of the mutations within the thalassemic population that is source of great phenotypic variability: higher levels of globin transgene expression are required to treat $\beta^{0}$-thalassemia compared with milder form of thalassemia.

Furthermore, in the same set of globin mutations additional mechanisms, potentially associated with genetic modifiers and/or other unknown factors, can determine dramatically variable clinical courses of the disease (Renzo Galanello and Antonio Cao with their valuable work have greatly contributed to knowledge in this field). ${ }^{57-59}$

This raises concern that some patients, based on their genetic profiles and endogenous hemoglobin production, might be better candidates for lentiviral-based therapies than others. This is especially important in light of the intrinsic ability of the specific vectors used in the different clinical trials to express sufficient amount of the therapeutic protein to cure severe thalassemias at a low vector copy.

Analysis of erythroid progenitors transduced with different amounts of lentiviral vectors could be extremely useful for testing the potential of each lentiviral construct prior to myeloablation and transplant. With this aim, the group of Rivella recently developed an in vitro protocol, which could predict the total amount of hemoglobin and the subsequent number of vector copies/cell required to reverse the thalassemic phenotype in a large pool of patient's samples that exhibited phenotypic variability of the disease. ${ }^{46}$

\section{Clinical trials}

Altogether, these results from several laboratories demonstrated the efficacy of globin gene transfer in the treatment of animal models and cell cultured of $\beta$ thalassemia, paving the way to assess globin gene transfer in selected patients who lack an HLA-matched donor. The first clinical trial using a SIN-LV vector to transfer a globin gene into bone marrow cells from patients with $\beta$-thalassemia was initiated in 2007 in Paris by the group of P. Leboulch and is still open. ${ }^{60,61}$ The lentiviral vector that was used, termed LentiGlobin, encodes a mutated adult $\beta$-gene $\left(\beta \mathrm{A}^{(\mathrm{T} 870)}\right)$ distinguishable from transfused $\beta$-globin because of an anti-sickling mutation at the $87^{\text {th }}$ amino acid. The vector was flanked by two copies of the 250 bp core of the cHS4 chromatin insulator. To date two patients have been treated: autologous cells were harvested from bone marrow, and the recipients were conditioned with full myeloablation with busulfan. The treatment was unsuccessful for the first patient, in that, owing to delayed hematological recovery and cytopenia related toxicity, he received nonmanipulated back-up cells for rescue and was reconstituted by unmodified thalassemic marrow cells. The second participant, a 18-year old male at the time of treatment, was affected by severe $\beta^{\mathrm{E}} / \beta^{0}$-thalassemia and began on regular transfusion therapy at age 3 because of severe and poorly tolerated anemia. The patient received the transduced bone marrow cells in early June of 2007 and became transfusion independent one year after gene transfer. The transduction efficiency of bulk CD34+ cells was approximately $30 \%$ and an average of 0.6 vector genomes/ transduced cell were found in his transduced bone marrow CD34+. The contribution of vector-encoded $\beta$-globin total $\mathrm{Hb}$ was estimated to be $3 \mathrm{~g} / \mathrm{dL}$, consistent with preclinical mouse studies. Although this patient stabilized at $9-10 \mathrm{~g} / \mathrm{dL}$ of $\mathrm{Hb}$, the outcome constitutes only a partial success of the gene therapy. This is due to the fact that the therapeutic $\mathrm{Hb}-\beta \mathrm{A}^{(\mathrm{T} 87 \mathrm{Q})}$ in this patient contributed only one third of the total $\mathrm{Hb}$ synthesized, while $\mathrm{HbE}$ and $\mathrm{HbF}$ accounted equally for the remaining $\mathrm{Hb}^{61}$ In addition, up to $50 \%$ of the $\mathrm{LV}$-derived $\mathrm{Hb}$ chains were produced from a single clonally expanded myeloid progenitor cell. This clonal dominance resulted from an insertional mutagenesis event in which the vector had integrated within the third intron of HMGA2 gene (high mobility group AT-hook 2) and gave rise to aberrant splicing of the third exon of the host gene onto a cryptic splice acceptor site within the core cHS4 insulator elements present in the LV-LTRs.

The aberrant splicing resulted in production of a truncated HMGA2 mRNA devoid of let-7 miRNA regulatory target sequences and in a protein product encoded by only the first three exons of the gene at highly elevated levels, with consequent downstream disturbances in gene function. The expression was reported to be erythroblast-specific, as HMGA2 mRNA was undetectable in granulocyte-monocyte cells. However, the clonal dominance of HMGA2 gene is represented in all populations in similar proportions (erythroblasts, granulocytemonocyte and LTC-IC).

The authors have hypothesized that this dominance is due to a transient expression of HMGA2 in a myeloid-restricted LT-HSC during $\beta$-LCR priming, before the $\beta$-LCR becomes restricted to the erythroid lineage. ${ }^{62}$

It is possible that, in this case, the oligoclonal reconstitution of the bone marrow has contributed to the clonal expansion of one of the few cells containing the vector (only 24 insertion sites have been highlighted). In this case, the frequency of the clone should stabilize or even decrease as a result of the exhaustion of the clone itself. As consequence, also the high-level expression associated to this clone should run out with the consequent loss of effectiveness of the treatment. In contrast, the clone could continue to expand emphasizing the nature of insertional oncogenesis of this event. Only a long-term follow-up of the patient will be able to shed light on these two hypotheses.

This expansion has been stable over several years to the present time, the patient is currently leukemia-free despite the prolonged clonal expansion and continues to produce an additional 2 to $3 \mathrm{~g} / \mathrm{dL}$ of hemoglobin comprising the vector-encoded $\beta^{(\mathrm{T} 870)}$-globin chain.

Given the special nature of outcomes in this case it is therefore not possible to deduce whether the vector used is capable to eventually ameliorate the condition of patients with $\beta$ thalassemia major, who possess little or no $\beta$ globin chains. Nevertheless, the gene therapy approach has great potential for success, as evidenced by the fact that this patient no longer needs transfusion therapy, does not manifest any malignant or pre-malignant state and has significantly improved quality of life.

At least two other groups have announced plans to carry out similar trials in the United States (http://oba.od.nih.gov/oba/rac/).

The source of HSCs, the conditions of $e x$ vivo cell manipulation and transduction are among the parameters that influence the outcome of the treatment. Although steady state bone marrow CD34+ cells were used as the source of HSCs for gene transfer in the first globin gene transfer trial, ${ }^{61}$ others group, including our own, are evaluating whether cytokine mobilization of peripheral blood CD34+ cells in patients with $\beta$-thalassemia might be safe and effective as a way to collect a greater number of HSCs.

In a pilot trial of CD34+ cells mobilization in adults with $\beta$-thalassemia, recently conducted at Memorial Sloan-Kettering Cancer Center (MSKCC) in New York, Sadelain and co-workers have demonstrated the feasibility of collecting a sufficient number of CD34+ cells mobilized with G-CSF in thalassemia major patients and validated an effective procedure for $\beta$-globin gene transfer. ${ }^{63}$ These findings provided the basis for the implementation of the first gene therapy trial in the United States in patients with severe hereditary globin disorders. The trial (registered at ClinicalTrials.gov under NCT01639690) already started at the beginning of 2013 at MSKCC and it is a multicenter phase I/II clinical trial that involves other European centers including our own. The trial is offered to patients with transfusion-dependent $\beta$ thalassemia who lack a matched, related donor. ${ }^{64}$ 


\section{Conclusions}

The severe $\beta$-thalassemias are still invalidating, often lethal disorders, for which a curative therapy is justified. The allogeneic HSCT from HLA-matched sibling results in a high likelihood of long-term disease-free survival mostly in pediatric patients. The remaining patients who lack of HLA-matched donor or those affected by mild or moderate iron overload and liver complications have a higher risk of morbidity or mortality if they pursue allogeneic HSCT. For these patients, the globin gene transfer in autologous stem cells offers the prospect of a cure since the efficient delivery of globin genes using LVs led: to amelioration of $\beta$-thalassemia murine models, and to the success of the first clinical trial in France. Nevertheless, more patients and a longer follow-up are necessary in order to establish whether the gene therapy may be safer than conventional allogeneic HSC transplantation. The unique pathology of $\beta$-thalassemia makes necessary to pay more attention to assess the optimal level of ablation, the source of HSCs, and cell dose in order to ensure effective engraftment of gene-engineered cells, reducing both the hematopoietic and the nonhematopoietic toxicity.

The risk of insertional oncogenesis in stem cell gene therapy with lentiviral vectors needs to be addressed together with vector configurations for increasing biosafety. Great efforts are being made to make realistic other future perspectives such as safe harbors and homologous recombination. Regardless the need for constantly improving vector design, a lot of attention has been drawn also towards strategies that result in higher numbers of genetically modified HSCs, that will in turn contribute to the HSC pool in the patient.

The latter, together with extensive research towards alternative HSC, such as iPS cells, will undoubtedly put the bases for more successful clinical trials.

\section{References}

1. Modell B, Darlison M. Global epidemiology of haemoglobin disorders and derived service indicators. Bull World Health Organ 2008;86:480-7.

2. Flint J, Harding RM, Boyce AJ, Clegg JB. The population genetics of the hemoglobinopathies in clinical haematology. Baillieres Clin Haematol 1998;11:1-51.

3. Weatherall DJ. The Thalassemias in the molecular basis of blood diseases. Philadelphia, PA: Saunders; 2001.

4. Rigano P, Pecoraro A, Calzolari R, et al.
Desensitization to hydroxycarbamide following long-term treatment of thalassaemia intermedia as observed in vivo and in primary erythroid cultures from treated patients. Br J Haematol 2010;151:509-15.

5. Borgna-Pignatti $C$. The life of patients with thalassemia major. Haematol 2010;95:345-8.

6. Restivo Pantalone G, Renda D, Valenza F, et al. Hepatocellular carcinoma in patients with thalassaemia syndromes: clinical characteristics and outcome in a long term single centre experience. Br J Haematol 2010;150:245-7.

7. Weatherall DJ, Clegg JB. Thalassemia: a global public health problem. Nat Med 1996;2:847-9.

8. Modell B, Khan M, Darlison M, et al. Improved survival of thalassaemia major in the UK and relation to $2^{*}$ cardiovascular magnetic resonance. J Cardiovasc Magn Reson 2008;10:1-8.

9. Thomas ED, Buckner CD, Sanders JE, et al. Marrow transplantation for thalassaemia. Lancet 1982;2:227-9.

10. Lucarelli G, Andreani M, Angelucci E. The cure of thalassemia by bone marrow transplantation. Blood Rev 2002;16:81-5.

11. Gaziev D, Polchi P, Galimberti M, et al. Graft-versus-host disease after bone marrow transplantation for thalassemia: an analysis of incidence and risk factors. Transplantation 1997;63:854-60.

12. La Nasa G, Argiolu F, Giardini C, et al. Unrelated bone marrow transplantation for $\beta$-thalassemia patients, the experience of the Italian bone marrow transplant group. Ann N Y Acad Sci 2005;1054:186-95.

13. Jaing TH, Hung IJ, Yang CP, et al. Unrelated cord blood transplantation for thalassaemia: a single-institution experience of 35 patients. Bone Marrow Transplant 2012;47:33-9.

14. Angelucci E. Hematopoietic stem cell transplantation in thalassemia. Hematology Am Soc Hematol Educ Program 2010;2010:456-62.

15. Naldini L. Ex vivo gene transfer and correction for cell based therapies. Nat Rev Genet 2011;12:301-15.

16. Riviere I, Dunbar CE, Sadelain M. Hematopoietic stem cell engineering at a crossroads. Blood 2012;19:1107-16.

17. Mercola KE, Cline MJ. The potentials of inserting new genetic information. $\mathrm{N}$ Engl J Med 1980;303:1297-300.

18. Lisowski L, Sadelain M. Current status of globin gene therapy for the treatment of $\beta$ thalassaemia. Br J Haematol 2008;141: 335-45.

19. Kohn DB, Sadelain M, Dunbar C, et al. American Society of Gene Therapy (ASGT) ad hoc subcommittee on retroviral-mediated gene transfer to hematopoietic stem cells. Mol Ther 2003;8:180-7.

20. Dzierzak EA, Papayannopoulou T, Mulligan RC.Lineage-specific expression of a human $\beta$-globin gene in murine bone marrow transplant recipients reconstituted with retrovirus-transduced stem cells. Nature 1988;331:35-41.

21. Karlsson S, Bodine DM, Perry L, et al. Expression of the human $\beta$-globin gene following retroviral-mediated transfer into multipotential hematopoietic progenitors of mice. Proc Natl Acad Sci 1988;85:6062-6.

22. Bender MA, Gelinas RE, Miller AD. A majority of mice show long-term expression of a human $\beta$-globin gene after retrovirus transfer into hematopoietic stem cells. Mol Cel Biol 1989;9:1426-34.

23. Novak U, Harris EAS, Forrester W, et al. High-level $\beta$-globin expression after retroviral transfer of locus activation regioncontaining human $\beta$ - globin gene derivatives into murine erythroleukemia cells. Proc Natl Acad Sci 1990;87:3386-90.

24. Grosveld F, van Assendelft GB, Greaves DR, Kollias G. Position-independent, high-level expression of the human $\beta$-globin gene in transgenic mice. Cell 1987;51:975-85.

25. Plavec I, Papayannopoulou T, Maury C, et al. A human $\beta$-globin gene fused to the human $\beta$-globin locus control region is expressed at high levels in erythroid cells of mice engrafted with retrovirus-transduced hematopoietic stem cells. Blood 1993;81:1384-92.

26. Emery DW, Chen H, Li Q, Stamatoyannopoulos G. Development of a condensed locus control region cassette and testing in retrovirus vectors for A $\gamma$-globin. Blood Cells Mol Dis 1998;24:322-39.

27. Leboulch P, Huang GMS, Humphries RK, et al. Mutagenesis of retroviral vectors transducing human $\beta$-globin gene and $\beta$-globin locus control region derivatives results in stable transmission of an active transcriptional structure. EMBO J 1994;13:3065-76.

28. Sadelain M, Wang CHJ, Antoniou M, et al. Generation of a high-titer retroviral vector capable of expressing high levels of the human $\beta$-globin gene. PNAS 1995;92: 6728-32.

29. Emery DW, Chen H, Li Q, et al. Development of virus vectors for gene therapy of $\beta$ chain hemoglobinopathies: flanking with a chromatin insulator reduces $\gamma$-globin gene silencing in vivo. Blood 2002;100:2012-19.

30. Bodine DM, Karlsson S, Nienhuis AW. Combination of interleukins 3 and 6 preserves stem cell function in culture and enhances retrovirus-mediated gene transfer into hematopoietic stem cells. PNAS 1989;86:8897-901.

31. Ellis J, Pannell D. The $\beta$-globin locus control region versus gene therapy vectors: a 
struggle for expression. and ultimately committed investigators migrated to the use of lentiviral vectors because of the advantages discussed in the next section. Clin Genet 2001;59:17-24.

32. Naldini L, Blomer U, Gallay P, et al. In vivo gene delivery and stable transduction of nondividing cells by a lentiviral vector. Science 1996;272:263-7.

33. Uchida N, Sutton RE, Friera AM, et al. HIV, but not murine leukemia virus, vectors mediate high efficiency gene transfer into freshly isolated G0/G1 human hematopoietic stem cells. PNAS 1998;95:11939-44.

34. Miyoshi H, Blömer U, Takahashi M, et al. Development of a self-inactivating lentivirus vector. J Virol 1998;72:8150-7.

35. Montini E, Cesana D, Schmidt M, et al. Hematopoietic stem cell gene transfer in a tumor-prone mouse model uncovers low genotoxicity of lentiviral vector integration. Nat Biotechnol 2006;24:687-96.

36. Arumugam PI, Scholes J, Perelman N, et al. Improved human $\beta$-globin expression from selfinactivating lentiviral vectors carrying the chicken hypersensitive site- 4 (cHS4) insulator element. Mol Ther 2007;15:1863-71.

37. Mitchell RS, Beitzel BF, Schroder AR, et al. Retroviral DNA integration: ASLV, HIV, and MLV show distinct target site preferences. PLoS Biol 2004;2:E234.

38. Beard BC, Dickerson D, Beebe K, et al. Comparison of HIV-derived lentiviral and MLV-based $\gamma$ retroviral vector integration sites in primate repopulating cells. Mol Ther 2007;15:1356-65.

39. De Palma M, Montini E, Santoni de Sio FR, et al. Promoter trapping reveals significant differences in integration site selection between MLV and HIV vectors in primary hematopoietic cells. Blood 2005;105:230715.

40. Schwarzwaelder K, Howe SJ, Schmidt M, et al. $\gamma$ retrovirus-mediated correction of SCID-X1 is associated with skewed vector integration site distribution in vivo. J Clin Invest 2007;117:2241-9.

41. Cartier N, Hacein-Bey-Abina S, Bartholomae CC, et al. Hematopoietic stem cell gene therapy with a lentiviral vector in X-linked adrenoleukodystrophy. Science 2009;326:818-23.

42. Biffi A, Bartolomae CC, Cesana D, et al. Lentiviral vector common integration sites in preclinical models and a clinical trial reflect a benign integration bias and not oncogenic selection. Blood 2011;117:5332-9.

43. Deichmann A, Hacein-Bey-Abina S, Schmidt $\mathrm{M}$, et al. Vector integration is nonrandom and clustered and influences the fate of lymphopoiesis in SCID-X1 gene therapy. J Clin Invest 2007;117:2225-32.

44. Emery DW. The use of chromatin insulators to improve the expression and safety of integrating gene transfer vectors. Hum Gene Ther 2011;22:761-74.

45. Miccio A, Poletti V, Tiboni F, et al The GATA1-HS2 enhancer allows persistent and position-independent expression of a $\beta$-globin transgene. PLoS One 2011;6:1-13.

46. Breda L, Casu C, Gardenghi S, et al. Therapeutic hemoglobin levels after gene transfer in $\beta$-thalassemia mice and in hematopoietic cells of $\beta$-thalassemia and sickle cells disease patients. PLoS One 2012;7:1-16.

47. D'Apolito D, Baiamonte E, Bagliesi M, et al. The sea urchin sns5 insulator protects retroviral vectors from chromosomal position effects by maintaining active chromatin structure. Mol Ther 2009;17:1434-41.

48. Acuto S, Di Marzo R, Calzolari R, et al. Functional characterization of the sea urchin sns chromatin insulator in erythroid cells. Blood Cells Mol Dis 2005; 35:339-44.

49. May C, Rivella S, Callegari J, et al. Therapeutic haemoglobin synthesis in $\beta$ thalassaemic mice expressing lentivirusencoded human $\beta$-globin. Nature 2000; 406:82-6.

50. Rivella S, May C, Chadburn A, et al. A novel murine model of Cooley anemia and its rescue by lentiviral-mediated human $\beta$-globin gene transfer. Blood 2003;101:2932-9.

51. Imren S, Payen E, Westerman KA, et al. Permanent and panerythroid correction of murine $\beta$-thalassemia by multiple lentiviral integration in hematopoietic stem cells. PNAS 2002;99:14380-5.

52. Persons DA, Hargrove PW, Allay ER, et al. The degree of phenotypic correction of murine $\beta$-thalassemia intermedia following lentiviral mediated transfer of a human g-globin gene is influenced by chromosomal position effects and vector copy number. Blood 2003;101:2175-83.

53. Hanawa H, Yamamoto M, Zhao $\mathrm{H}$, et al. Optimized lentiviral vector design improves titer and transgene expression of vectors containing the chicken $\beta$-globin locus HS4 insulator element. Mol Ther 2009;17:667-74.
54. Miccio A, Cesari R, Lotti F, et al. In vivo selection of genetically modified erythroblastic progenitors leads to long term correction of $\beta$-thalassemia. Proc Natl Acad Sci 2008;105:10547-52.

55. Puthenveetil G, Scholes J, Carbonell D, et al. Successful correction of the human $\beta$ thalassemia major phenotype using a lentiviral vector. Blood 2004;1043:445-53.

56. Roselli EA, Mezzadra R, Frittoli MC, et al. Correction of $\beta$-thalassemia major by gene transfer in hematopoietic progenitors of pediatric patients. EMBO Mol Med 2010;2:315-28.

57. Cao A, Galanello R, Rosatelli MC. Genotype-phenotype correlations in $\beta$-thalassemias. Blood Rev 1994;8:1-12.

58. Cao A, Moi P, Galanello R. Recent advances in $\beta$-thalassemias. Pediatr Rep 2011;3:6578.

59. Danjou F, Anni F, Perseu L, et al .Genetic modifiers of $\beta$-thalassemia and clinical severity as assessed by age at first transfusion. Haematologica 2012;97:989-93.

60. Bank A, Dorazio R, Leboulch P. A phase I/II clinical trial of $\beta$-globin gene therapy for $\beta$-thalassemia. Ann NY Acad Sci 2005; 1054:308-16.

61. Cavazzana-Calvo M, Payen E, Negre 0, et al. Transfusion independence and HMGA2 activation after gene therapy of human $\beta$ thalassaemia. Nature 2010;467:318-22.

62. Payen E, Leboulch P. Advances in stem cell transplantation and gene therapy in the $\beta$ hemoglobinopathies. Hematology Am Soc Hematol Educ Program 2012; 2012:276-83.

63. Boulad F, Wang X, Qu J, et al. Safe mobilization of CD34+ cells in adults with $\beta$ thalassemia and validation of effective globin gene transfer for clinical investigation. Blood 2014. [Epub ahead of print]

64. Sadelain M, Riviere I, Wang X, et al. Strategy for a multicenter phase I clinical trial to evaluate globin gene transfer in $\beta$ thalassemia. Ann N Y Acad Sci 2010;1202: $52-8$. 